\title{
OPEN Gliadin-mediated green preparation of hybrid zinc oxide nanospheres with antibacterial activity and low toxicity
}

\author{
Qun Wang ${ }^{1}$, Peng $\mathrm{Ji}^{1 \bowtie}$, Yansheng Yao ${ }^{2 \bowtie}$, Yi Liu ${ }^{1}$, Yajie Zhang ${ }^{1}$, Xianglong Wang ${ }^{1}$, \\ Yuhang Wang ${ }^{1} \&$ Jinyan $\mathrm{Wu}^{3}$
}

The development of inorganic antibacterial agents that impart antibacterial properties to biomaterials has attracted wide attention. The paper introduced a kind of hybrid nanosphere antibacterial agent composed of wheat gliadin (WG) and zinc oxide ( $\mathrm{ZnO}$ ), with antibacterial efficacy and low toxicity. The ZnO/WG hybrid nanospheres were environment-friendly integrated by molecular self-assembly co-precipitating and freeze-drying transformation, and were characterized using X-ray diffraction (XRD), Fourier transform infrared spectroscopy (FTIR), scanning electron microscope (SEM), atomic absorption spectroscopy (AAS), specific surface and pore size analysis, bacteriostasis test, reactive oxygen species (ROS) determination and safety evaluation. It was found that the prepared hybrid nanospheres were composed of two components, WG and ZnO, with a diameter scope of 100-200 $\mathrm{nm}$; the content of $\mathrm{ZnO}$ in the hybrid nanospheres can reach 46.9-70.2\% (w/w); the bacteriostasis tests proved that the prepared ZnO/WG nanospheres generating ROS, have a significant inhibitory effect on E. coli and S. aureus; furthermore, the ZnO/WG nanospheres are relatively safe and highly biocompatible in cells and mice. Therefore, the prepared novel ZnO/WG hybrid nanospheres were supposed to apply in the preparation of anti-infective wound dressings, tissue engineering skin scaffold materials, food, and cosmetics preservatives, and so on.

Metal-based drugs, especially inorganic nanomaterials used in implantable biomaterials, have been studied as a next-generation nanomedicine $e^{1,2}$. However, implanted biomaterials, long or short periods of close contact with human tissue, have the problem of causing various bacterial infections ${ }^{3-7}$. Therefore, the improvement of the antibacterial properties of biomaterials has become the key to their wider application in clinical medicine.

It is one of the methods to improve the antimicrobial properties of biomaterials by inserting antimicrobial substances into biomaterials. However, when loaded into biomaterials, the antibiotics will be quickly exhausted, and this approach can easily make bacteria resistant; besides, although the antibacterial effect of quaternary ammonium salts is better, the application is also limited, due to the hemolytic effect ${ }^{8}$.

Inorganic antibacterial agents are durable and less toxic ${ }^{9}$. Metal or metal oxide nanoparticles are currently the main research directions of inorganic antibacterial agents ${ }^{10-12}$, especially research concerning microwaveocaloric therapy, sonodynamic treatment, and photoactivated therapy as effective and rapid antibacterial methods has attracted tremendous interest ${ }^{13}$. Nano- $\mathrm{ZnO}$ has attracted extensive attention due to its advantages, such as long-term antibacterial, safety ${ }^{14}$, stability, excellent angiogenesis, and promotion of proliferation of adult dermal fibroblast cells ${ }^{15-17}$.

Composite nanomaterials, obtained by integrating organic and inorganic components, have broad application prospects in many fields. Notably, these nanocomposite particles not only inherited the superior characteristics of the raw materials, but also obtained other multi-functional characteristics that are not available in a single component. For example, a growing number of researchers pay attention to the design of core-shell structured composite nanospheres $^{18,19}$, which can reduce their toxicity by covering other materials ${ }^{20-22}$, and increase their biocompatibility and water dispersibility ${ }^{23-25}$.

\footnotetext{
${ }^{1}$ College of Pharmacy and Chemistry \& Chemical Engineering, Jiangsu Provincial Key Laboratory of Chiral Pharmaceutical Chemicals Biologically Manufacturing, Taizhou University, Taizhou 225300, Jiangsu, China. ${ }^{2}$ Department of Endocrinology, The Affiliated Taixing People's Hospital of Medical College, Yangzhou University, Taixing 225400, China. ${ }^{3}$ Department of Dermatology, Huashan Hospital, Fudan University, Jing'an District, Shanghai 200040, China. ${ }^{\circledR}$ email: jipeng0213@163.com; yaoyansheng.yc@163.com
} 


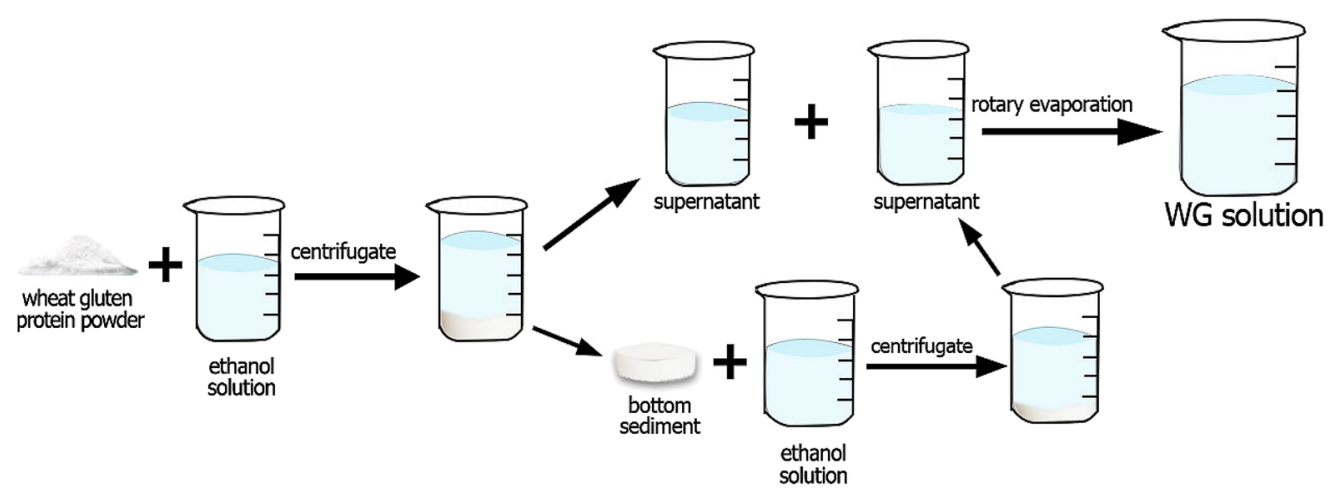

a. Process diagram of WG solution

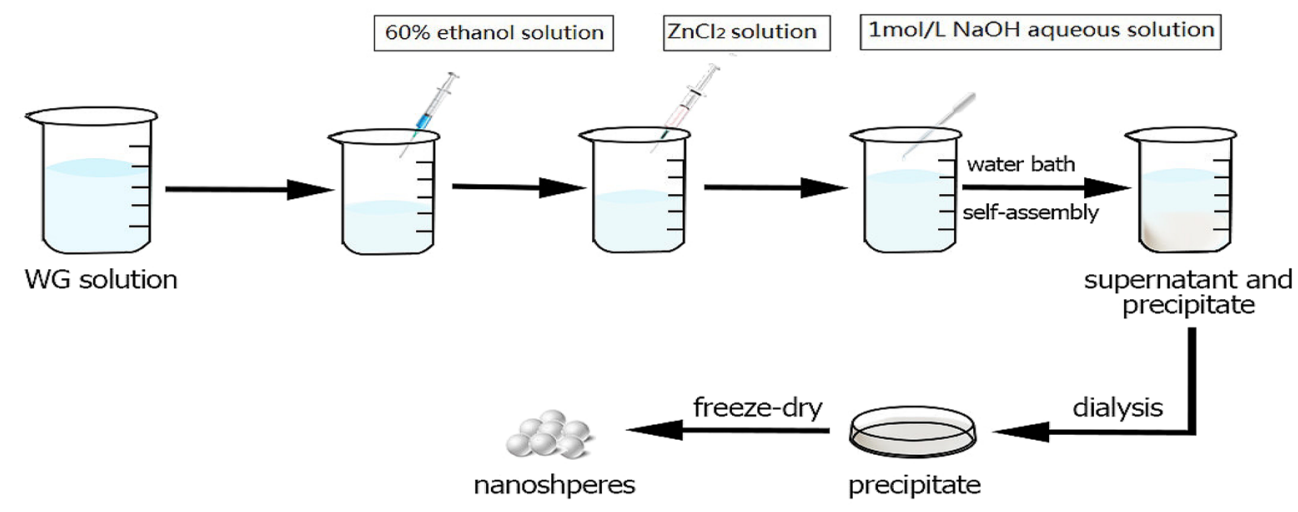

b. Process diagram of $\mathrm{ZnO} / \mathrm{WG}$ nanospheres

$$
\begin{gathered}
\mathrm{Zn}^{2+}+\mathrm{NH}_{2}-\mathrm{R}-\mathrm{COOH} \longrightarrow\left[\mathrm{Zn}\left(\mathrm{NH}_{2}-\mathrm{R}-\mathrm{COOH}\right)_{4}\right]^{2+} \\
{\left[\mathrm{Zn}\left(\mathrm{NH}_{2}-\mathrm{R}-\mathrm{COOH}\right)_{4}\right]^{2+}+2 \mathrm{OH}^{-} \longrightarrow\left[\mathrm{Zn}(\mathrm{OH})_{2}\left(\mathrm{NH}_{2}-\mathrm{R}-\mathrm{COOH}\right)_{2}\right] \downarrow+2\left(\mathrm{NH}_{2}-\mathrm{R}-\mathrm{COOH}\right)} \\
2\left[\mathrm{Zn}(\mathrm{OH})_{2}\left(\mathrm{NH}_{2}-\mathrm{R}-\mathrm{COOH}\right)_{2}\right] \downarrow \stackrel{\text { frezze-drying }}{\longrightarrow} 2\left[\mathrm{ZnO}\left(\mathrm{NH}_{2}-\mathrm{R}-\mathrm{COOH}\right)_{2}\right] \downarrow+\mathrm{H}_{2} \mathrm{O} \downarrow
\end{gathered}
$$

(note: $\mathrm{NH}_{2}-\mathrm{R}-\mathrm{COOH}$, representing $\mathrm{WG}$ proteins or polypeptides)

\section{c. Possible reactions concerned with the formation of $\mathrm{ZnO} / \mathrm{WG}$ nanospheres}

Figure 1. Preparation process (a,b) and possible reaction mechanism (c).

In this paper, a hybrid nanosphere of inorganic antimicrobial $\mathrm{ZnO}$ and WG was prepared by self-assembly co-precipitating and freeze-drying transformation. This study is aimed to develop an anti-infective pharmaceutical for surgical trauma therapy and to develop a new tissue-engineered skin with persistent anti-infective properties $^{26-28}$.

\section{Results and discussion}

Preparation of ZnO/WG nanospheres. Generally speaking, the most common synthesis methods of $\mathrm{ZnO}$ nanoparticles were in the presence of surfactants or precipitating agents being associated with potential toxic effects against the environment and living orgnisms ${ }^{29}$. Attempting to address this issue, the preparation process of $\mathrm{ZnO} / \mathrm{WG}$ nanospheres, as illustrated in Fig. 1a,b, was carried out in an environment-friendly manner, avoiding extreme reaction conditions, harmful chemicals, and toxic by-products, which would contribute better 


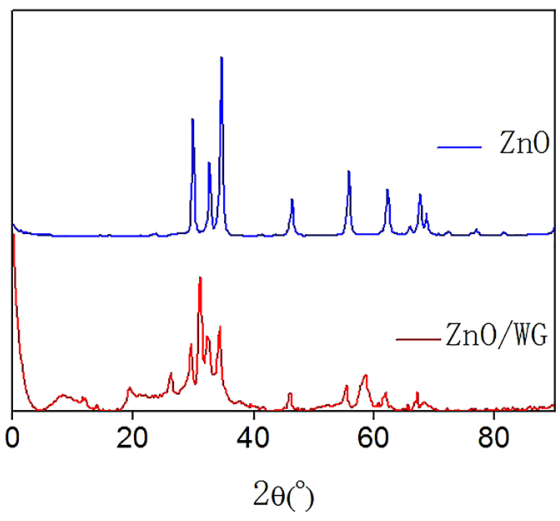

a. XRD patterns of $\mathrm{ZnO}$
and $\mathrm{ZnO} / \mathrm{WG}$ nanoparticles

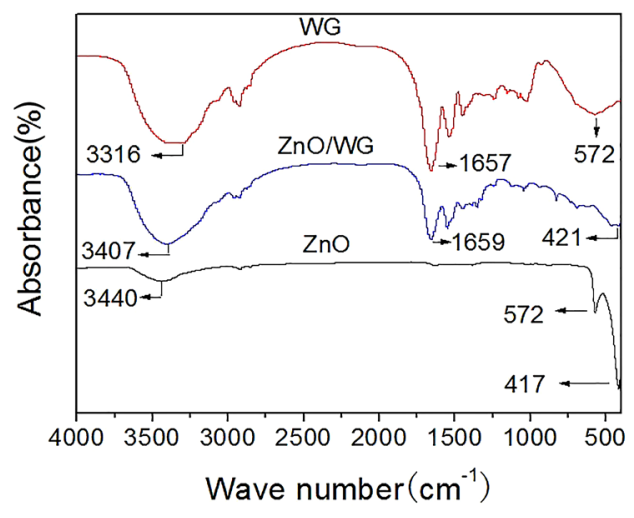

b. FTIR graphs of nano-ZnO, WG powder and $\mathrm{ZnO} / \mathrm{WG}$ nanospheres

Figure 2. XRD patterns (a) and FTIR graphs (b).

biocompatibility to the final applications of the nanospheres. The WG molecules here used, rich in amino, carboxyl, and hydroxyl groups, are stabilizing agents triggering the self-assembly co-precipitating of hybrid nanoparticles.

Substantially, according to molecular orbital theory, $\mathrm{Zn}^{2+}$ has four empty orbitals and are $\mathrm{SP}^{3}$ hybrids, so $\mathrm{Zn}^{2+}$ are easy to form tetra-ligand compounds when there are enough ligands as amine ligand et al. Therefore, the possible formation mechanism of $\mathrm{ZnO} / \mathrm{WG}$ nanospheres is illustrated as follows:

The formation process of $\mathrm{ZnO} / \mathrm{WG}$ nanospheres was shown in the above three formulations (Fig. 1c). Firstly, complexes were self-assembled formed by $\mathrm{Zn}^{2+}$ and WG polypeptides; secondly, two hydroxyl groups substituted two $\mathrm{NH}_{2}-\mathrm{R}-\mathrm{COOH}$ ligands, which resulted in the co-precipitating formation of zinc hydroxic conjugating with WG polypeptides; finally, the co-precipitates lost water and transformed to the $\mathrm{ZnO} / \mathrm{WG}$ nanospheres during the freeze-drying process.

Actually, the transformation between the zinc hydroxic conjugates and $\mathrm{ZnO} / \mathrm{WG}$ nanospheres should be confirmed by the XRD test and FTIR test, as analyzed below.

XRD and FTIR analysis. As shown in Fig. 2a, due to the presence of $\mathrm{ZnO}$ crystals in the sample, the XRD pattern of the nano-ZnO has nine characteristic peaks, including $31.8^{\circ}, 34.5^{\circ}, 36.4^{\circ}, 47.8^{\circ}, 56.8^{\circ}, 62.9^{\circ}, 66.5^{\circ}$, $68.0^{\circ}, 69.1^{\circ}$. And same peaks also appeared in $\mathrm{ZnO} / \mathrm{WG}$ nanospheres, including $31.8^{\circ}, 34.5^{\circ}, 36.4^{\circ}, 47.8^{\circ}, 56.8^{\circ}$, $62.9^{\circ}, 66.5^{\circ}, 68.0^{\circ}, 69.1^{\circ}$, indicating that $\mathrm{ZnO}$ crystals also exist in the $\mathrm{ZnO} / \mathrm{WG}$ nanosphere $\mathrm{s}^{30,31}$. Furthermore, in the XRD patterns of the $\mathrm{ZnO} / \mathrm{WG}$ sample, peaks appeared at $8.28^{\circ}, 19.5^{\circ}, 33.2^{\circ}, 58.6^{\circ}$, different from the characteristic peaks of $\mathrm{ZnO}$, were possibly due to the two-dimensional lattice of zinc basic salt, a kind of nano-hybrid formed by the interaction between $\mathrm{Zn}^{2+}$ and WG molecules ${ }^{32}$.

In Fig. $2 b, 3000-3600 \mathrm{~cm}^{-1}$ is the composite peak formed by the $\mathrm{O}-\mathrm{H}$ stretching vibration of the $-\mathrm{COOH}$ group and the $\mathrm{N}-\mathrm{H}$ stretching vibration of the $-\mathrm{NH}_{2}$ group; peaks near $1659 \mathrm{~cm}^{-1}$ are the $\mathrm{C}=\mathrm{O}$ stretching vibration peak of the amide bond, peaks near $1540 \mathrm{~cm}^{-1}$ are formed by the $\mathrm{N}-\mathrm{H}$ stretching vibration of the amide bond, peaks near $1450 \mathrm{~cm}^{-1}$ are formed by the $\mathrm{C}-\mathrm{N}$ stretching of the amide bond; these peaks are typical characteristic peaks of proteins. Furthermore, due to the stretching vibration of $\mathrm{Zn}-\mathrm{O}$, a peak near $417 \mathrm{~cm}^{-1}$ appeared the characteristic peak of $\mathrm{ZnO}$. Therefore, according to the comparison among the three FTIR graphs, it was proved that the $\mathrm{ZnO} / \mathrm{WG}$ nanospheres were composed of $\mathrm{ZnO}$ and $\mathrm{WG}$, which is consistent with the $\mathrm{XRD}$ analysis results.

Morphology observation and analysis of ZnO/WG nanospheres. The SEM images of $\mathrm{ZnO} / \mathrm{WG}$ nanospheres were shown in Fig. 3. When the WG concentration in the preparation process is $2 \mathrm{mg} / \mathrm{mL}, 6 \mathrm{mg} /$ $\mathrm{mL}, 8 \mathrm{mg} / \mathrm{mL}, 10 \mathrm{mg} / \mathrm{mL}$, the nanospheres are spherical or ellipsoidal, with no holes on the surface, but there is a certain amount of adhesion between the particles; when the WG concentration is $4 \mathrm{mg} / \mathrm{mL}$, the shape of the prepared nanospheres appeared a more irregular spherical shape with rough surface, but the independence between the particles is better. In conclusion, the common profiles of the prepared hybrid nanospheres were revealed: the shape is nearly spherical, the particle size range is $100-200 \mathrm{~nm}$, but the adhesion between the particles is relatively serious. The separation process between the supernatant and precipitates, as well as the freeze-drying method, might have a great influence on the adhesion of $\mathrm{ZnO} / \mathrm{WG}$ nanospheres, which should be further researched in the following work.

According to the above observation of morphology, the particle size changed with the WG concentration increasing. Furthermore, as shown in Fig. 4, the $\mathrm{ZnO}$ content of the five different samples varied with the concentration of WG used in the preparation process, and its range reached $46.9-70.2 \%$ (w/w). Especially, when the WG concentration was $4 \mathrm{mg} / \mathrm{mL}$, the average particle size of the corresponding nanospheres reached a maximum 

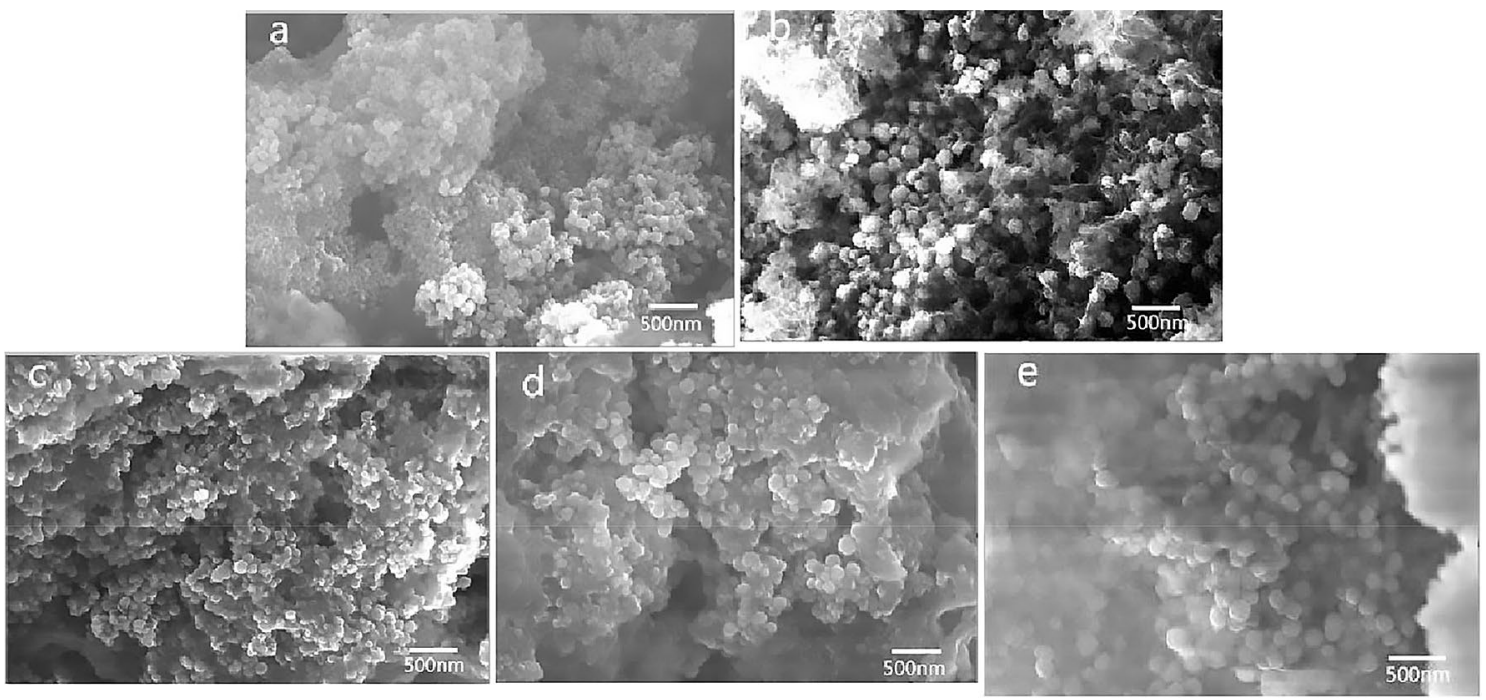

Figure 3. $\mathrm{ZnO} / \mathrm{WG}$ nanospheres prepared by different concentrations of WG [WG concentrations while preparation: (a) $2 \mathrm{mg} / \mathrm{mL}$; (b) $4 \mathrm{mg} / \mathrm{mL}$; (c) $6 \mathrm{mg} / \mathrm{mL}$; (d) $8 \mathrm{mg} / \mathrm{mL}$; (e) $10 \mathrm{mg} / \mathrm{mL}$ ].

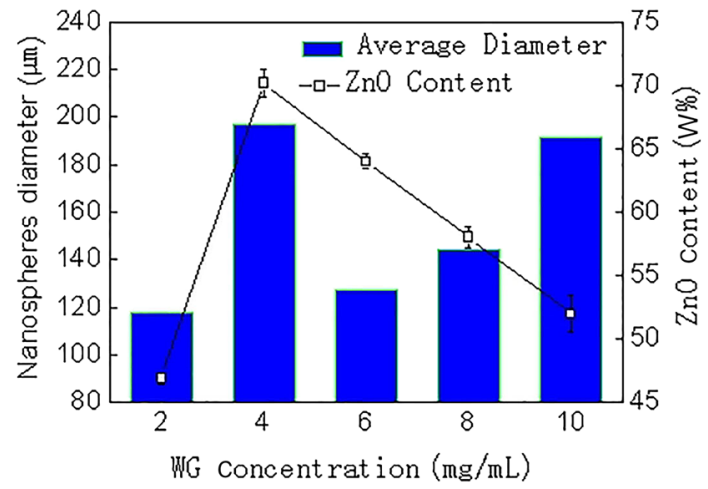

Figure 4. Effect of WG concentrations on the diameter and $\mathrm{ZnO}$ content of nanospheres.

value of $197 \mathrm{~nm}$, and the $\mathrm{ZnO}$ content also reached a maximum value of 70.2\% (w/w). Therefore, the particles size and the content of the $\mathrm{ZnO}$ were functions of the concentration of WG.

Specific surface area and pore size analysis. As shown from the isothermal adsorption and desorption curves in Fig. 5, there is a ring caused by desorption lag at the relative pressure $0.8-1.0$ which is a feature of mesoporous materials, indicating that the prepared $\mathrm{ZnO} / \mathrm{WG}$ hybrid nanospheres are porous structures. According to the pore size distribution curves measured by the $\mathrm{BJH}$ method, the pore size distribution of samples a, b, c, and d ranged from 2 to $30 \mathrm{~nm}$ which was typical of mesoporous materials, and mainly distributed in the narrow range of $2-10 \mathrm{~nm}$ indicating a good consistency. However, the pore size distribution of sample e was wide, with different characteristics at $2-7 \mathrm{~nm}$ and $7-70 \mathrm{~nm}$, respectively indicating poor pore size homogeneity, which may be caused by more WG protein macromolecules in the nanospheres.

Table 1 shows the most frequent pore size $(\mathrm{BJH})$, specific surface area (BET), and pore volume of the 5 groups of samples. As the concentration of WG increasing from 2 to $10 \mathrm{mg} / \mathrm{mL}$, the BJH desorption most frequent pore diameter of the prepared $\mathrm{ZnO} / \mathrm{WG}$ hybrid nanospheres becomes firstly smaller (a,b,c,d) and lastly bigger (e), and respectively, the BET specific surface area and BJH desorption pore (D:1.7-300 nm) volume become firstly larger (a,b,c,d) and lastly smaller (e). According to the value of micropore volume measured by the HK method, there were small volumes of micropores in all 5 samples, but they accounted for a small proportion of the total volume, which was consistent with the results of pore size distribution curves in Fig. 5.

Analysis of antibacterial test results. As shown in Fig. 6, the antibacterial effect of the prepared hybrid nanospheres is represented by a circular sterile area. When the same volume of medicine ( $25 \mu \mathrm{L}$ per sample) with different concentrations, was dripped onto the agar plate, the inhibitory effect of the nanoparticles on microorganisms can be indirectly tested depending on the concentration change of the suspension. The detailed results were given in Table 1 and discussed as follows. 

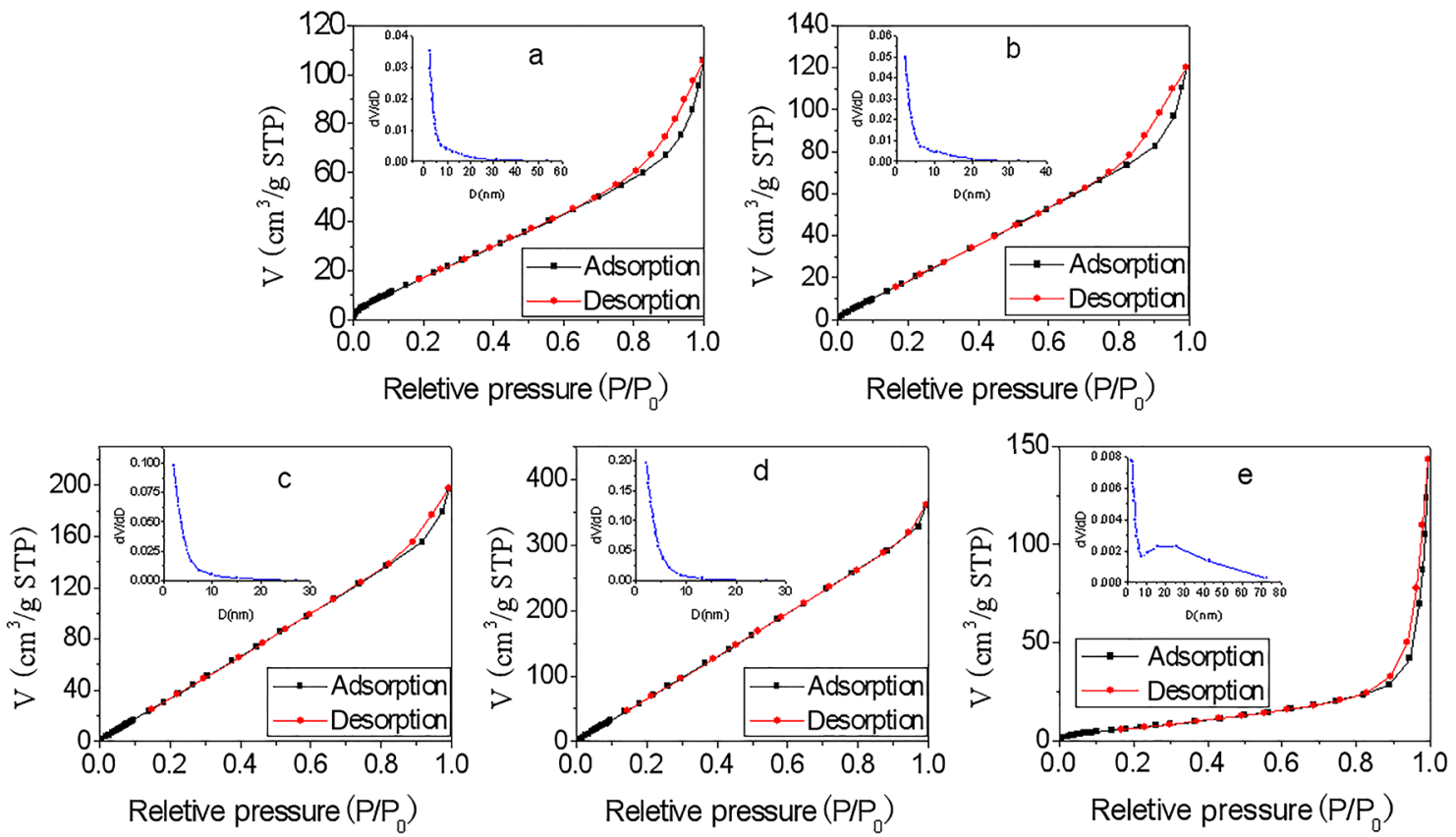

Figure 5. Isothermal adsorption and desorption curves $\left(\mathrm{N}_{2}\right)$ and pore size distributions (BJH desorption) [WG concentrations while preparation: (a) $2 \mathrm{mg} / \mathrm{mL}$; (b) $4 \mathrm{mg} / \mathrm{mL}$; (c) $6 \mathrm{mg} / \mathrm{mL}$; (d) $8 \mathrm{mg} / \mathrm{mL}$; (e) $10 \mathrm{mg} / \mathrm{mL}$ ].

\begin{tabular}{|l|l|l|l|l|}
\hline Sample & $\begin{array}{l}\text { BET specific } \\
\text { surface area }\left(\mathbf{m}^{2} / \mathbf{g}\right)\end{array}$ & $\begin{array}{l}\text { BJH Desorption Most Frequent } \\
\text { Pore Diameter }(\mathbf{d V} / \mathbf{d D}) / \mathbf{n m})\end{array}$ & $\begin{array}{l}\text { BJH Desorption Pore }(\mathrm{D}: 1.7-300 ~ \mathbf{n m}) \\
\text { Volume }\left(\mathbf{c m}^{\mathbf{3}} / \mathbf{g}\right)\end{array}$ & $\begin{array}{l}\text { HK Micropore }(\mathrm{D}<2 \\
\mathbf{n m}) \text { Volume }\left(\mathbf{c m}^{3} / \mathbf{g}\right)\end{array}$ \\
\hline a & 52.795 & 2.308 & 0.191 & 0.022 \\
\hline b & 70.963 & 2.223 & 0.234 & 0.021 \\
\hline c & 215.180 & 2.149 & 0.402 & 0.037 \\
\hline d & 523.886 & 2.127 & 0.753 & 0.070 \\
\hline e & 21.669 & 2.215 & 0.232 & 0.008 \\
\hline
\end{tabular}

Table 1. The data concerned with specific surface area and pore size. WG concentrations while preparation: (a) $2 \mathrm{mg} / \mathrm{mL}$; (b) $4 \mathrm{mg} / \mathrm{mL}$; (c) $6 \mathrm{mg} / \mathrm{mL}$; (d) $8 \mathrm{mg} / \mathrm{mL}$; (e) $10 \mathrm{mg} / \mathrm{mL}$.

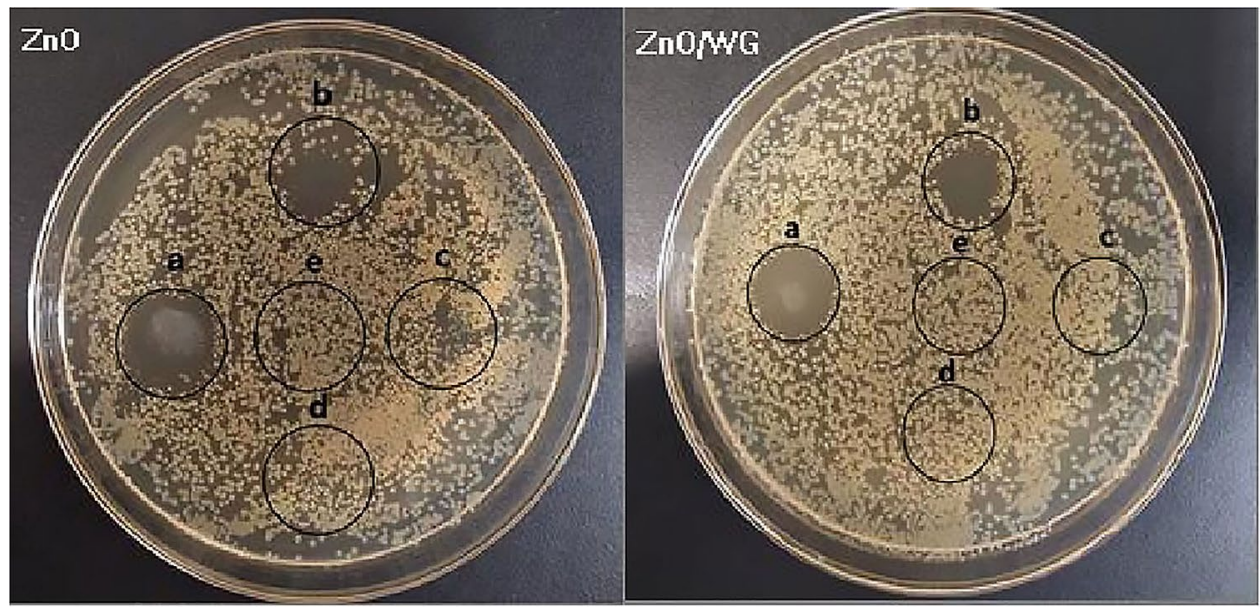

Figure 6. Representative sample agar plates showing the zones of inhibition to $S$. aureus (Suspension concentrations of samples: (a) $10 \mathrm{mg} / \mathrm{mL}$; (b) $5 \mathrm{mg} / \mathrm{mL}$; (c) $2 \mathrm{mg} / \mathrm{mL}$; (d) $1 \mathrm{mg} / \mathrm{mL}$; (e) saline). 


\begin{tabular}{|c|c|c|c|c|c|c|c|c|c|}
\hline \multirow[b]{2}{*}{ Sample } & \multirow[b]{2}{*}{ Saline } & \multicolumn{4}{|c|}{$\begin{array}{l}\mathrm{ZnO} \text { nano-power suspension } \\
\text { concentration }(\mathrm{mg} / \mathrm{mL})\end{array}$} & \multicolumn{4}{|c|}{$\begin{array}{l}\text { The concentration of } \mathrm{ZnO} / \mathrm{WG} \\
\text { hybrid nanosphere suspension } \\
(\mathrm{mg} / \mathrm{mL})\end{array}$} \\
\hline & & 10 & 5 & 2 & 1 & 10 & 5 & 2 & 1 \\
\hline E. coli & - & ++ & ++ & ++ & - & ++ & + & - & - \\
\hline S.aureus & - & +++ & ++ & + & - & +++ & ++ & - & - \\
\hline Antibacterial effect & $\times$ & $\sqrt{ }$ & $\sqrt{ }$ & $\sqrt{ }$ & $\times$ & $\sqrt{ }$ & $\sqrt{ }$ & $x$ & $x$ \\
\hline
\end{tabular}

Table 2. Antibacterial effect of $\mathrm{ZnO} / \mathrm{WG}$ nanospheres on $E$. coli and $S$. aureus. While $\mathrm{D} \geq 10 \mathrm{~mm}$, and no bacteria colony in the inhibition zone, recorded as +++ ; while $\mathrm{D} \geq 10 \mathrm{~mm}$, but appeared visible colonies in the inhibition zone, recorded as ++; while $10 \mathrm{~mm}>\mathrm{D} \geq 5 \mathrm{~mm}$, and no colony in the inhibition zone, it is recorded as ++; while $10 \mathrm{~mm}>\mathrm{D} \geq 5 \mathrm{~mm}$, but appeared visible colonies in the circle, it is recorded as +; while $\mathrm{D}<5 \mathrm{~mm}$, recorded as -.

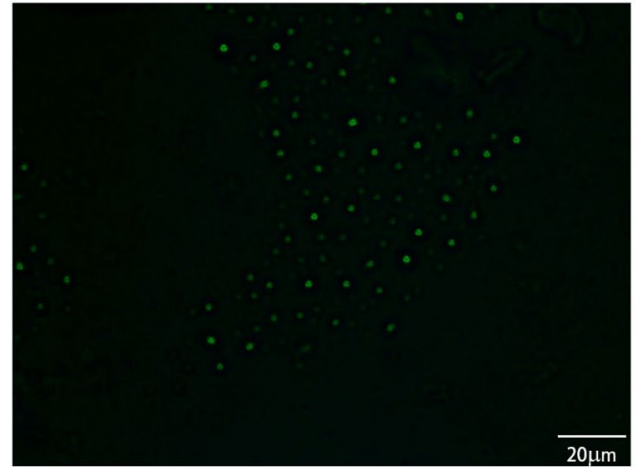

\section{ZnO/WG nanosphere}

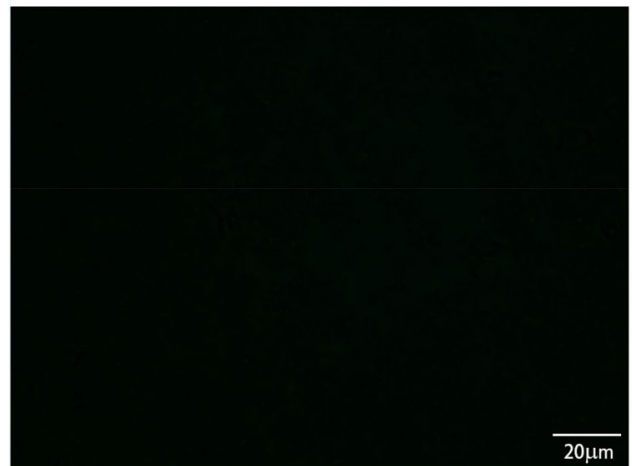

PBS control
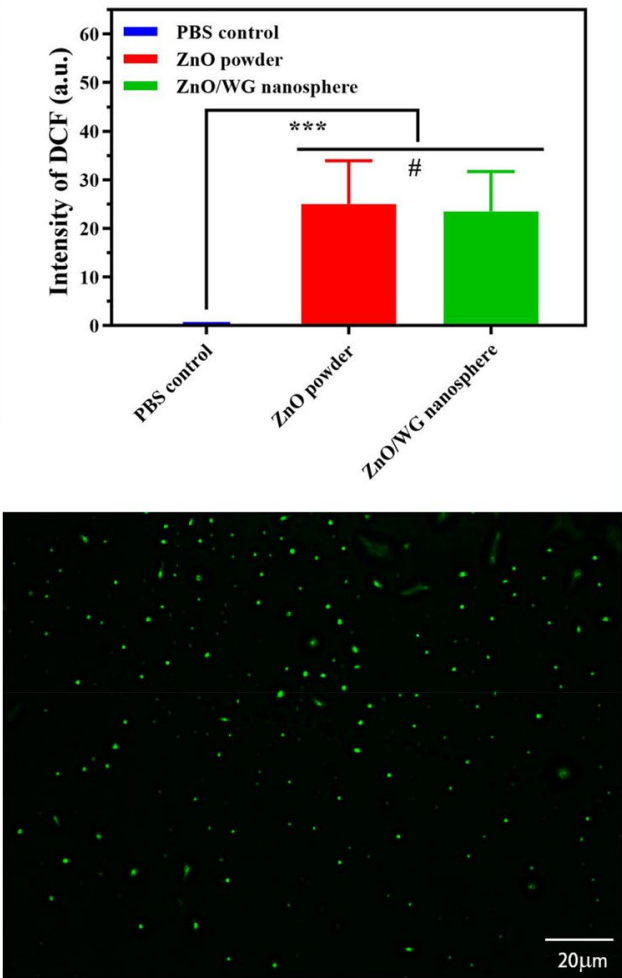

ZnO powder

Figure 7. The results of ROS determination (Scale bar:20 $\mu \mathrm{m}$, Results are expressed as the mean \pm SD; corresponding DCF fluorescence value $\left.{ }^{* * *} p<0.005,{ }^{\#} p>0.5\right)$.

Taking $\mathrm{ZnO} / \mathrm{WG}$ hybrid nanospheres with a $\mathrm{ZnO}$ content of $70 \%(\mathrm{w} / \mathrm{w})$ as an example, it can be found from Table 2: Negative control (saline) has no bacteriostatic activity; positive control ( $\mathrm{ZnO}$ nanopowder), at a concentration of $2 \mathrm{mg} / \mathrm{mL}$, has a certain bacteriostatic effect on $E$. coli and $S$. aureus; $\mathrm{ZnO} /$ WG hybrid nanospheres, at a concentration of $5 \mathrm{mg} / \mathrm{mL}$, have a certain bacteriostatic effect on $E$. coli and $S$. aureus. At a concentration of 10 $\mathrm{mg} / \mathrm{mL}$, Both the hybrid nanospheres and the $\mathrm{ZnO}$ nanopowder have an obvious antibacterial effect on E. coli and $S$. aureus. This shows that the prepared $\mathrm{ZnO} / \mathrm{WG}$ hybrid nanospheres have antibacterial activity increasing with the concentration ${ }^{33,34}$.

Besides, compared with $\mathrm{ZnO}$ nano-powder, at the low concentration, $2 \mathrm{mg} / \mathrm{mL}$ and $5 \mathrm{mg} / \mathrm{mL}$, the bacteriostatic effect of $\mathrm{ZnO} / \mathrm{WG}$ hybrid nanospheres on E. coli reduced; but at the concentration of $10 \mathrm{mg} / \mathrm{mL}$, the antibacterial activity on S. aureus is equivalent. This shows that: Increasing the concentration of $\mathrm{ZnO} / \mathrm{WG}$ hybrid nanospheres, can produce the equivalent bacteriostatic effect as the $\mathrm{ZnO}$ nano-power, which is beneficial to the application of $\mathrm{ZnO} / \mathrm{WG}$ hybrid nanospheres, as a candidate antibacterial agents, in the fields of antibacterial biomaterials, food, and cosmetics preservatives, etc ${ }^{35,36}$. 


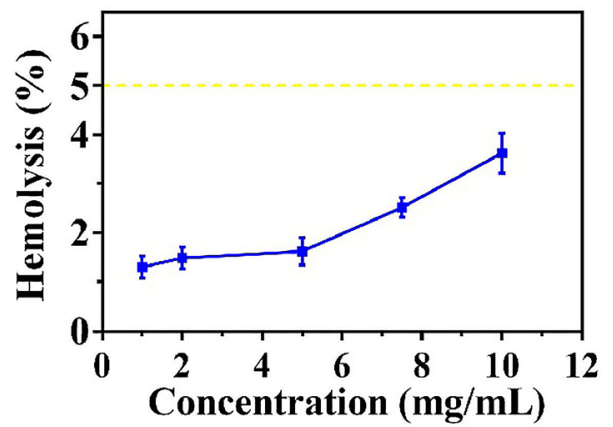

a. Hemolysis testing results of ZnO/WG nanospheres at various concentrations

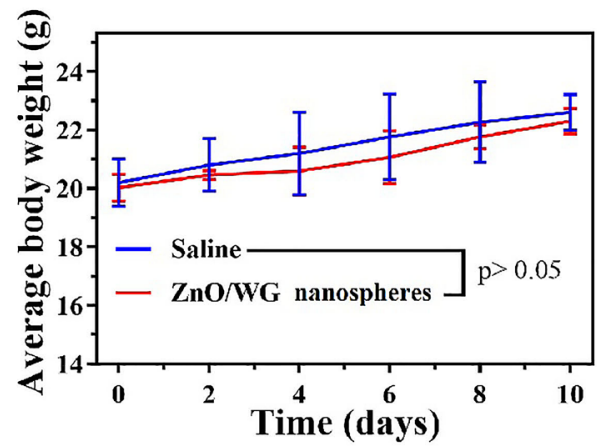

\section{b. Average bodyweights of $\mathrm{ZnO} / \mathrm{WG}$ nanospheres during 10-day $(n=3)$}

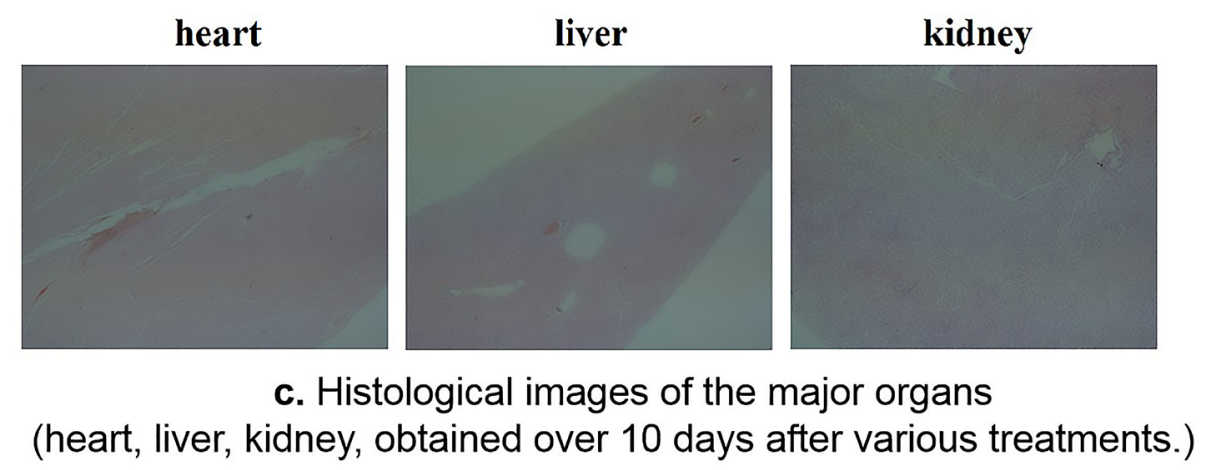

Figure 8. Safety evaluation.

Antimicrobial mechanism. A ROS determination test as shown in Fig. 7, was carried out to research the antibacterial mechanism. From the fluorescent probe photos, it was found that there were no fluorescent spots in PBS negative control group, while a large number of fluorescent spots appeared in samples of $\mathrm{ZnO}$ nanopowder and $\mathrm{ZnO} / \mathrm{WG}$ hybrid microspheres which appeared stronger intensity of the intracellular ROS signal than that of PBS for $S$. aureus $(p<0.005)$. It was due to the intracellular ROS stimulating the conversion of DCFH-DA to a green fluorescent product $(\mathrm{DCF})^{37}$.

Photoresponsive antimicrobial materials combat pathogenic bacteria via ROS, which is a general term describing the chemical species formed by incomplete oxygen reduction. ROS mainly includes superoxide anion $\left(\cdot \mathrm{O}_{2}\right)$, hydrogen peroxide $\left(\mathrm{H}_{2} \mathrm{O}_{2}\right)$, singlet oxygen $\left({ }^{1} \mathrm{O}_{2}\right)$, and hydroxyl radical $(\cdot \mathrm{OH})$. It is widely accepted that ROS can bind to and damage bacterial membranes and cell walls, thereby destroying the bacterial defense system. ROS can also penetrate bacterial membranes, entering the cells to destroy proteins and lipids and, thus, directly or indirectly disrupting cellular respiration and other physiological activities ${ }^{38-40}$.

Furthermore, it has been reported that $\mathrm{Zn}^{2+}$ has an excellent antibacterial effect and can enhance oxidative stress and combine with the bacteria to change the fluidity of the bacterial membrane ${ }^{41}$. Nevertheless, as shown in Fig. 6, the method of the antimicrobial test was a bacteriostatic circle, therefore there was no appropriate acidic micro-environment for quickly releasing zinc ions converted from $\mathrm{ZnO}$, and the nanospheres and bacteria stayed on the solid agar plate, had difficulty directly contact with each other, which resulted in weak interaction between the nanospheres and S. aureus.

Consequently, the antimicrobial properties of the prepared hybrid nanospheres might not be directly attributed to the release of zinc ions, as well as the interaction of the nanospheres and bacteria, but be mainly attributed to the ROS which moved quickly to contact with bacteria, and then damaged bacterial membranes and cell walls.

Analysis of safety evaluation. To further evaluate the potential of $\mathrm{ZnO} / \mathrm{WG}$ nanospheres in biomedical applications, the biocompatibility of the $\mathrm{ZnO} / \mathrm{WG}$ nanospheres in vivo was examined in a mouse model. The breakdown of red blood cells collected from the mice was negligible for $\mathrm{ZnO} / \mathrm{WG}$ nanospheres up to $10 \mathrm{mg} /$ $\mathrm{mL}$ (Fig. 8a). For preparation, no significant weight loss was observed in the mice throughout the trial period (Fig. 8b), and the retention of $\mathrm{ZnO} / \mathrm{WG}$ nanospheres in the heart, liver, and kidneys did not cause severe side effects, according to $\mathrm{H} \& \mathrm{E}$ staining (Fig. 8c), elucidating no serious adverse effects and elucidating good biocompatibility of $\mathrm{ZnO} / \mathrm{WG}$ nanospheres in vivo ${ }^{42}$. These results generally indicated that the administration of $\mathrm{ZnO} /$ WG nanospheres was biocompatible in mice ${ }^{43,44}$. 


\section{Conclusion}

Generally, $\mathrm{ZnO}$ /WG nanospheres were prepared by zinc chloride solution using the self-assembly-freeze-drying method, under the induction of WG, at a suitable $\mathrm{pH}$ value.

Based on the XRD and FTIR analysis, it was confirmed that the nanosphere was composed of $\mathrm{ZnO}$ and WG. Based on the SEM test, it was observed that the shapes of $\mathrm{ZnO} / \mathrm{WG}$ nanospheres were nearly spherical, with a diameter range of 100-200 $\mathrm{nm}$. According to AAS data, it was determined that the content of $\mathrm{ZnO}$ in the nanospheres reaches $46.9-70.2 \%(\mathrm{w} / \mathrm{w})$. The bacteriostasis tests proved that the prepared $\mathrm{ZnO} / \mathrm{WG}$ nanospheres generating ROS, have a significant inhibitory effect on E. coli and S. aureus. Moreover, the hemolysis assays and $\mathrm{H} \& \mathrm{E}$ staining demonstrated that $\mathrm{ZnO} / \mathrm{WG}$ nanospheres had relatively low toxicity in cells and mice.

\section{Materials and methods}

Materials. Gluten protein powder (5000 Da, food-grade, Jiangsu Zhihui Biotechnology Co., Ltd., China); zinc chloride $\left(\mathrm{ZnCl}_{2}\right)$, ethanol, sodium hydroxide $(\mathrm{NaOH})$, acetic acid (analytically pure, Sinopharm Group Chemical Reagent Co., Ltd., China); Zinc (99.99\%, premium-grade, Sinopharm Group Chemical Reagent Co., Ltd., China); Concentrated hydrochloric acid (analytical grade, Wuxi City Yasheng Chemical Co., Ltd., China), ROS detection kit (Beijing Bio Lebo Technology Co., Ltd, China).

Female Balb/c mice (5-6 weeks old) were obtained from the Laboratory Animal Center of China Pharmaceutical University. All animal procedures were performed following the Guidelines for the Care and Use of Laboratory Animals of Taizhou University and approved by the Animal Ethics Committee of Taizhou University.

FTIR-650 Fourier Transform Infrared Spectrometer (FTIR) (FTIR-650, Tianjin Gangdong Technology Co., Ltd., China); Ultima IV X-ray Diffraction Analyzer (XRD) (Ultima IV, Japan Rigaku Co., Ltd., Japan); Sigma-500 Field Emission Scanning Electron Microscope (SEM) (Sigma-500, Carl Zeiss, Germany); SCIENTZ-10 N freeze dryer (Ningbo Xinzhi Biotechnology Co., Ltd., China); TAS-990AFG atomic absorption spectrophotometer (AAS) (Beijing Purkinje General Instrument Co., Ltd., China); Inverted fluorescence microscope (OLYMPUS IX51, Japan); Specific surface and pore size analyzer (JW-BK100).

Preparation methods. Preparation of wheat gliadin $(W G)$ solution. The process diagram of wheat gliadin (WG) solution is shown in Fig. 1a. About $4 \mathrm{~g}$ wheat gluten protein powder was slowly poured into $200 \mathrm{~mL} 70 \%$ ethanol solution after stirring for $2 \mathrm{~h}$, and centrifuged to obtain supernatant and precipitate; bottom sediment was poured into $200 \mathrm{~mL} \mathrm{70 \%} \mathrm{ethanol} \mathrm{solution} \mathrm{under} \mathrm{stirring.} \mathrm{In} \mathrm{the} \mathrm{medium,} \mathrm{stirring} \mathrm{was} \mathrm{continued} \mathrm{for} \mathrm{another}$ $2 \mathrm{~h}$, and the supernatant was centrifuged and combined with the previous supernatant, and concentrated by rotary evaporation to obtain a WG solution with a concentration of $1 \%(\mathrm{w} / \mathrm{w})$.

Preparation of $\mathrm{ZnO} / \mathrm{WG}$ nanospheres. The process diagram of $\mathrm{ZnO} / \mathrm{WG}$ nanospheres is shown in Fig. $1 \mathrm{~b}$. Firstly, the above prepared solution of WG, was filled in 5 beakers, each $50.00 \mathrm{~mL}$ respectively, in which 200.00 $\mathrm{mL}, 75.00 \mathrm{~mL}, 33.50 \mathrm{~mL}, 12.50 \mathrm{~mL}$, and $0 \mathrm{~mL}$ of $60 \%$ ethanol were added subsequently, to obtain five kinds of WG solutions with different concentrations of $2 \mathrm{mg} / \mathrm{mL}, 4 \mathrm{mg} / \mathrm{mL}, 6 \mathrm{mg} / \mathrm{mL}, 8 \mathrm{mg} / \mathrm{mL}, 10 \mathrm{mg} / \mathrm{mL}$. And then $125.00 \mathrm{~mL}, 62.50 \mathrm{~mL}, 41.75 \mathrm{~mL}, 31.25 \mathrm{~mL}, 25.00 \mathrm{~mL}$ solutions, each containing $250 \mathrm{mg} \mathrm{ZnCl}$, were respectively added into the five kinds of WG solutions; and subsequently, the $\mathrm{pH}$ value of the five WG solutions was adjusted to $8-8.9$ using $1 \mathrm{~mol} / \mathrm{L} \mathrm{NaOH}$ aqueous solution. And thus the mixed solutions were rested for $60 \mathrm{~min}$, at a 37 ${ }^{\circ} \mathrm{C}$ water bath, until the self-assembled particles were completely precipitated. Lastly, the mixed suspension was dialyzed to neutrality in $60 \%$ ethanol, using a dialysis membrane (molecular weight cutoff of $12,000 \mathrm{Da}$ ), in which the retained precipitates were transferred to a Petri dish and freeze-dried at $-40{ }^{\circ} \mathrm{C}$ in a freeze dryer (SCIENTZ-10 N, Ningbo Xinzhi Biotechnology Co., Ltd.) for 24 h, to obtain the hybrid nanospheres.

Property characterization. The XRD spectrum of the dried nanosphere sample was measured by X-ray diffractometer: line source of $\mathrm{Cu}$ targeted $\mathrm{Ka}$, the wavelength of $0.15406 \mathrm{~nm}$, scanning step length of $0.03^{\circ}$, scanning range of $10^{\circ}-90^{\circ}$.

The infrared spectrum of the sample was measured by FTIR: The dried nanospheres and dried potassium bromide solid powder are mixed, grinded, and compressed to carry out a spectral scan.

The scanning wavenumber range was $4000-500 \mathrm{~cm}^{-1}$; after dispersing the prepared dried nanospheres on conductive tape sticked to the aluminum plate, and vacuuming, SEM was used to observe and take photos.

AAS was used to determine the $\mathrm{Zn}$ element content in the sample, and then calculate the $\mathrm{ZnO}$ content (3 parallel samples). A particle size analysis software of Nano Measurer was used to measure the average particle size of the nanospheres (number of samples 40), based on the SEM photos.

The specific surface and pore size analyzer were used to analyze the specific surface area and pore size of the sample (Using $\mathrm{N}_{2}$ as the adsorption medium): Before analysis, the sample was vacuum degassed at $50{ }^{\circ} \mathrm{C}$ for $3 \mathrm{~h}$; the specific surface area of the sample was calculated by the Brunauer-Emmett-Teller (BET) model; the pore size distribution is calculated by the Barrett-Joyner-Halenda $(\mathrm{BJH})$ model; the pore volume of micropores (diameter $<2 \mathrm{~nm}$ ) is calculated by the HK/SF method; the pore volume of mesopores and macropores (diameter: $1.7-300 \mathrm{~nm}$ ) is calculated by the $\mathrm{BJH}$ model.

Evaluation of antimicrobial activity. Firstly the prepared $\mathrm{ZnO} / \mathrm{WG}$ hybrid nanosphere sample (containing a $\mathrm{ZnO}$ mass ratio of $70.2 \%$ ) and the positive control sample (commercially available nano- $\mathrm{ZnO}$ ) were subjected to ultraviolet irradiation sterilization. Then, in the ultra-clean workbench with the cleanliness of class $\mathrm{B}$, the dry particles of hybrid nanospheres were prepared into physiological saline suspensions of $10 \mathrm{mg} / \mathrm{mL}$, $5 \mathrm{mg} / \mathrm{mL}, 2 \mathrm{mg} / \mathrm{mL}, 1 \mathrm{mg} / \mathrm{mL}, 0 \mathrm{mg} / \mathrm{mL}$ (respectively marked as a, b, c, d, e). After the activated E. coli and $S$. 
aureus (approximately $10^{8} \mathrm{Cfu} / \mathrm{mL}$ ) were evenly coated on the agar solid medium (TSA) and standed still for 5 min until the bacterial suspension was absorbed by the agar plate, $25 \mu \mathrm{L}$ each of the above four different concentrations of nanosphere suspensions, as well as a negative control sample, were dropped into the TSA medium previously coated with bacteria. After about $10 \mathrm{~min}$ later until the nanoparticle suspensions were absorbed by the agar plate, the cultures were inverted in a $32^{\circ} \mathrm{C}$ microbial incubator and incubated for $24 \mathrm{~h}$, finally to observe whether there is an inhibition zone at the drop sites, record the diameter (D) of the appeared inhibition zone.

Determination of reactive oxygen species. Reactive oxygen species (ROS) were tested using DCFHDA fluorescent probe kit. The ROS of the prepared $\mathrm{ZnO} / \mathrm{WG}$ hybrid nanospheres were tested with PBS as the negative control and $\mathrm{ZnO}$ as the positive control. In brief, the testing procedures mainly included: reference substances and drugs were added to $S$. aureus bacterial solution of about $10^{8} \mathrm{CFU} / \mathrm{mL}$, and cultured $60 \mathrm{~min}$ in an incubator at $37^{\circ} \mathrm{C}$, then the bacteria were centrifuged to remove the substances such as drugs and culture solution with acidic PBS lotion to obtain bacteria containing reactive oxygen species; subsequently, DCFH-DA fluorescent probe was added and cultured at $37^{\circ} \mathrm{C}$ for $30 \mathrm{~min}$, then the extracellular DCFG-DA was washed off with PBS, and the bacterium suspension was observed and photographed using an inverted fluorescence microscope.

Safety evaluation. Hemolysis. $1 \mathrm{~mL}$ of the whole blood of the mice was taken and put into a $2 \mathrm{~mL}$ centrifuge tube containing $2.5 \mu \mathrm{L}$ of $2 \%$ heparin sodium and stirred slowly. Afterward, the same volume of saline solution was added and centrifuged at $1500 \mathrm{rpm}$ for $10 \mathrm{~min}$. The supernatant was removed and resuspended with $10 \mathrm{~mL}$ saline. The suspension was centrifuged at $1500 \mathrm{rpm}$ for $20 \mathrm{~min}$. The same process was repeated three times to obtain red blood cells ${ }^{23}$. Subsequently, $0.2 \mathrm{~mL}$ erythrocyte suspension was mixed with (I) $0.8 \mathrm{~mL}$ PBS as a negative control, (II) $0.8 \mathrm{~mL}$ deionized water as a positive control, and (III) $0.8 \mathrm{~mL}$ aqueous dispersion of $\mathrm{ZnO} /$ WG nanospheres $(1-10 \mathrm{mg} / \mathrm{mL})$. After incubation at $37^{\circ} \mathrm{C}$ for $1 \mathrm{~h}$ and centrifuged at $12,000 \mathrm{rpm}$ for $5 \mathrm{~min}$, the supernatants were taken to determine the optical density (OD value) in a microplate reader (Spark $10 \mathrm{M}$, Tecan, Zürich, Switzerland) at a wavelength of $540 \mathrm{~nm}$. The calculation formula of hemolysis ratio (Hr) is as follows: $\mathrm{Hr}$ $(\%)=($ ODs - ODn $/ O D p-O D n) \times 100 \%$, in which ODs, ODp, and ODn are the OD values of the samples, the positive control, and the negative control, respectively.

Histological studies. To further evaluate the potential of $\mathrm{ZnO} / \mathrm{WG}$ nanospheres in biomedical applications, we evaluated the possible biosafety and adverse reactions for 10 days. Female Balb/c mice were randomly divided into 2 groups $(\mathrm{n}=3)$, and Intragastric administration (1) $0.9 \mathrm{wt} \%$ saline, (2) $\mathrm{ZnO} / \mathrm{WG}$ nanospheres (10 mg/kg) every days. The body weight as an index of systemic toxicity was recorded and calculated every 2 days. After 10 days of treatment, major organs (including heart, liver, and kidney) were cut, half-sectioned, photographed and then placed in a buffered $4 \%$ formaldehyde solution overnight. Deparaffinized $5 \mu \mathrm{m}$ sections were stained with hematoxylin-eosin for further analysis.

Statistical analysis. Use SPSS Statistics 17.0 software to check all data and express them as mean \pm standard deviation (SD). Use Student's $t$-test to analyze statistical significance; ${ }^{*} p<0.05$ was considered the minimum meaning.

Received: 2 March 2021; Accepted: 22 April 2021

Published online: 14 May 2021

\section{References}

1. Jin, S. E. \& Jin, H. E. Synthesis, characterization, and three-dimensional structure generation of zinc oxide-based nanomedicine for biomedical applications. Pharmaceutics 11, 575. https://doi.org/10.3390/pharmaceutics11110575 (2019).

2. Das, S., Mitra, S., Khurana, S. M. P. \& Debnath, N. Nanomaterials for biomedical applications. Front. Life Sci. 7, 90-98. https://doi. org/10.1002/biot.202000574 (2013).

3. Bisht, G. \& Rayamajhi, S. ZnO nanoparticles: A promising anticancer agent. Nanobiomedicine 3, 387-393. https://doi.org/10.5772/ 63437 (2016).

4. Campoccia, D., Montanaro, L. \& Arciola, C. R. A review of the clinical implications of anti-infective biomaterials and infectionresistant surfaces. Biomaterials 34, 8018-8029. https://doi.org/10.1016/j.biomaterials.2013.07.048 (2013).

5. Corduas, F., Mancuso, E. \& Lamprou, D. A. Long-acting implantable devices for the prevention and personalised treatment of infectious, inflammatory and chronic diseases. J. Drug Deliv. Sci. Technol. 60, 101952. https://doi.org/10.1016/j.jddst.2020.101952 (2020).

6. Kuijer, R. et al. Assessing infection risk in implanted tissue-engineered devices. Biomaterials 28, 5148-5154. https://doi.org/10. 1016/j.biomaterials.2007.06.003 (2007).

7. Wei, T., Yu, Q. \& Chen, H. Antibacterial coatings: Responsive and synergistic antibacterial coatings: Fighting against bacteria in a smart and effective way. Adv. Healthc. Mater. 8, 1801381. https://doi.org/10.1002/adhm.201801381 (2019).

8. Song, W. \& Ge, S. Application of antimicrobial nanoparticles in dentistry. Molecules 24, 1033. https://doi.org/10.3390/molecules2 4061033 (2019).

9. Chen, R. et al. Antibacterial activity, cytotoxicity and mechanical behavior of nano-enhanced denture base resin with different kinds of inorganic antibacterial agents. Dent. Mater. J. 36, 693-699. https://doi.org/10.4012/dmj.2016-301 (2017).

10. Li, J. et al. Zinc-doped Prussian blue enhances photothermal clearance of Staphylococcus aureus and promotes tissue repair in infected wounds. Nat. Commun. 10, 4490. https://doi.org/10.1038/s41467-019-12429-6 (2019).

11. Bradley, E. L., Castle, L. \& Chaudhry, Q. Applications of nanomaterials in food packaging with a consideration of opportunities for developing countries. Trends Food Sci. Technol. 22, 604-610. https://doi.org/10.1016/j.tifs.2011.01.002 (2011).

12. Chaudhry, Q. et al. Applications and implications of nanotechnologies for the food sector. Food Addit. Contam. A 25, 241-258. https://doi.org/10.1080/02652030701744538 (2008).

13. Ren, Y. et al. Photoresponsive materials for antibacterial applications. Cell Rep. Phys. Sci. 1, 100245. https://doi.org/10.1016/j.xcrp. $2020.100245(2020)$. 
14. Ye, D. et al. ZnO-based nanoplatforms for labeling and treatment of mouse tumors without detectable toxic side Effect. ACS Nano 10, 4294-4300. https://doi.org/10.1021/acsnano.5b07846 (2016).

15. Carofiglio, M., Barui, S., Cauda, V. \& Laurenti, M. Doped zinc oxide nanoparticles: Synthesis, characterization and potential use in nanomedicine. Appl. Sci 10, 5194. https://doi.org/10.3390/app10155194 (2020).

16. Ahtzaz, S. et al. A study on the effect of zinc oxide and zinc peroxide nanoparticles to enhance angiogenesis-pro-angiogenic grafts for tissue regeneration applications. Mater. Des. 132, 409-418. https://doi.org/10.1016/j.matdes.2017.07.023 (2017).

17. Cui, L., Liang, J., Liu, H., Zhang, K. \& Li, J. Nanomaterials for angiogenesis in skin tissue engineering. Tissue Eng. Part B Rev. 26, 203-216. https://doi.org/10.1089/ten.TEB.2019.0337 (2020).

18. Xiong, $\mathrm{H}$. ZnO nanoparticles applied to bioimaging and drug delivery. Adv. Mater. 25, 5329-5335. https://doi.org/10.1002/adma. 201301732 (2013).

19. Zhang, Z. et al. Biodegradable ZnO@polymer core-shell nanocarriers: pH-triggered release of doxorubicin in vitro. Angew. Chem. Int. Ed. 52, 4127-4131. https://doi.org/10.1002/anie.201300431 (2013).

20. Song, Q., Peng, M., Wang, L., He, D. \& Ouyang, J. A fluorescent aptasensor for amplified label-free detection of adenosine triphosphate based on core-shell $\mathrm{Ag} @ \mathrm{SiO}_{2}$ nanoparticles. Biosens. Bioelectron. 77, 237-241. https://doi.org/10.1016/j.bios.2015.09.008 (2016).

21. Kim, M., Son, H., Kim, G., Park, K. \& Huh, Y. Redoxable heteronanocrystals functioning magnetic relaxation switch for activatable T1 and T2 dual-mode magnetic resonance imaging. Biomaterials 101, 121-130. https://doi.org/10.1016/j.biomaterials.2016. 05.054 (2016).

22. Iribarnegaray, V. et al. Magnesium-doped zinc oxide nanoparticles alter biofilm formation of Proteus mirabilis. Nanomedicine UK 14, 1551-1564. https://doi.org/10.2217/nnm-2018-0420 (2019).

23. Wang, $\mathrm{H}$. et al. Multifunctional PEG encapsulated $\mathrm{Fe}_{3} \mathrm{O}_{4} @$ silver hybrid nanoparticles: Antibacterial activity, cell imaging and combined photothermo/ chemo-therapy. J. Mater. Chem. B 1, 6225-6234. https://doi.org/10.1039/C3TB21055C (2013).

24. Ji, P. et al. ROS-mediated apoptosis and anticancer effect achieved by artesunate and auxiliary Fe(II) released from ferriferous oxide-containing recombinant apoferritin. Adv. Healthc. Mater. 8, 1900911. https://doi.org/10.1002/adhm.201900911 (2019).

25. Ji, P. et al. Hyaluronic acid hydrophilic surface rehabilitating curcumin nanocrystals for targeted breast cancer treatment with prolonged biodistribution. Biomater. Sci. UK 8, 462-472. https://doi.org/10.1039/C9BM01605H (2020).

26. Wang, J. et al. Bacterial species-identifiable magnetic nanosystems for early sepsis diagnosis and extracorporeal photodynamic blood disinfection. Nanoscale 10, 132-141. https://doi.org/10.1039/C7NR06373C (2018).

27. Ferrone, E., Araneo, R., Notargiacomo, A., Pea, M. \& Rinaldi, A. ZnO nanostructures and electrospun ZnO-polymeric hybrid nanomaterials in biomedical, health, and sustainability applications. Nanomater. Basel 9, 1449. https://doi.org/10.3390/nano9 101449 (2019)

28. Jatoi, A. W., Kim, I. S. \& Ogasawara, H. Characterizations and application of CA/ZnO/AgNP composite nanofibers for sustained antibacterial properties. Mater. Sci. Eng. C 105, 110077. https://doi.org/10.1016/j.msec.2019.110077 (2019).

29. Cruz, D. M. et al. Green nanotechnology-based zinc oxide ( $\mathrm{ZnO})$ nanomaterials for biomedical applications: A review. J. Phys. Mater. 3, 034005. https://doi.org/10.1088/2515-7639/ab8186 (2020).

30. Dwivedi, L. M. et al. Antibacterial nanostructures derived from oxidized sodium alginate-ZnO. Int. J. Biol. Macromol. 149, 13231330. https://doi.org/10.1016/j.ijbiomac.2020.02.011 (2020).

31. Ohira, T., Yamamoto, O., Iida, Y. \& Nakagawa, Z. Antibacterial activity of ZnO powder with crystallographic orientation. J. Mater. Sci. Mater. M. 19, 1407-1412. https://doi.org/10.1007/s10856-007-3246-8 (2008).

32. Biswick, T., Park, D., Shul, Y. \& Choy, J. P-coumaric acid-zinc basic salt nanohybrid for controlled release and sustained antioxidant activity. J. Phys. Chem. Solids 71, 647-649. https://doi.org/10.1016/j.jpcs.2009.12.058 (2010).

33. Silva, B. L., Caetano, B. L., Chiari-Andréo, B. G., Pietro, R. \& Chiavacci, L. A. Increased antibacterial activity of ZnO nanoparticles: Influence of size and surface modification. Colloid Surf. B 177, 440-447. https://doi.org/10.1016/j.colsurfb.2019.02.013 (2019).

34. Prasanna, V. L. \& Vijayaraghavan, R. Chemical manipulation of oxygen vacancy and antibacterial activity in ZnO. Mater. Sci. Eng. C 77, 1027-1034. https://doi.org/10.1016/j.msec.2017.03.280 (2017).

35. Li, Y. et al. Enhancing ZnO-NP antibacterial and osteogenesis properties in orthopedic applications: A review. Int. J. Nanomed. 15, 6247-6262. https://doi.org/10.2147/IJN.S262876 (2020).

36. Shi, L. et al. Synthesis, antibacterial activity, antibacterial mechanism and food applications of $\mathrm{ZnO}$ nanoparticles: A review. Food Addit. Contam. A 31, 173-186. https://doi.org/10.1080/19440049.2013.865147 (2014).

37. Courtney, C. et al. Potentiating antibiotics in drug-resistant clinical isolates via stimuli-activated superoxide generation. Sci. Adv. 3, e1701776. https://doi.org/10.1126/sciadv.1701776( (2017).

38. Li, J. et al. Light-activated rapid disinfection by accelerated charge transfer in red phosphorus/ZnO heterointerface. Small Methods 3, 1900048. https://doi.org/10.1002/smtd.201900048 (2019).

39. Xiang, Y. et al. Rapid and superior bacteria killing of carbon quantum dots/ZnO decorated injectable folic acid-conjugated PDA hydrogel through dual-light triggered ROS and membrane permeability. Small 15, 1900322. https://doi.org/10.1002/smll.20190 0322 (2019).

40. Huang, B. et al. Rapid bacteria capturing and killing by AgNPs/N-CD@ZnO hybrids strengthened photo-responsive xerogel for rapid healing of bacteria- infected wounds. Chem. Eng. J. 414, 128805. https://doi.org/10.1016/j.cej.2021.128805 (2021).

41. Xiang, Y. et al. A Z-scheme heterojunction of $\mathrm{ZnO} / \mathrm{CDots} / \mathrm{C} 3 \mathrm{~N} 4$ for strengthened photoresponsive bacteria-killing and acceleration of wound healing. J. Mater. Sci. Technol. 57, 1-11. https://doi.org/10.1016/j.jmst.2020.05.016 (2020).

42. Xu, X., Chen, Y., Zhang, Y., Yao, Y. \& Ji, P. Highly stable and biocompatible hyaluronic acid-rehabilitated nanoscale MOF-Fe(2+) induced ferroptosis in breast cancer cells. J. Mater. Chem. B 8, 9129-9138. https://doi.org/10.1039/D0TB01616K (2020).

43. Bitonto, V. et al. L-ferritin: A theranostic agent of natural origin for MRI visualization and treatment of breast cancer. J. Control. Release. 319, 300-310. https://doi.org/10.1016/j.jconrel.2019.12.051 (2020).

44. Alqahtani, M. S., Syed, R. \& Alshehri, M. Size-dependent phagocytic uptake and immunogenicity of gliadin nanoparticles. Polymers 12, 2576-2576. https://doi.org/10.3390/polym12112576 (2020).

\section{Acknowledgements}

This work was supported by the Key Program of Taizhou University (TZXY2014ZDKT010); Scientific Research Starting Foundation of Taizhou University (TZXY2020QDJJ009); Science and Technology Innovation Action Plan of Shanghai Science and Technology Commission (19441909900).

\section{Author contributions}

Q.W., P.J. and Y.Y. conceived the experiments, discussed the results, and wrote the main manuscript text. Q.W. independently prepared the Figs. 1c, 2, 3, 4, 5, 6, Tables 1 and 2. P.J. and Y.Y. co-prepared Figs. 7 and 8. Q.W. and X.W. co-prepared Fig. 1a,b. Y.Y., Y.L., Y.Z., X.W. and Y.W. conducted the experiments. J.W. analyzed the results. All authors reviewed the manuscript. 


\section{Competing interests}

The authors declare no competing interests.

\section{Additional information}

Correspondence and requests for materials should be addressed to P.J. or Y.Y.

Reprints and permissions information is available at www.nature.com/reprints.

Publisher's note Springer Nature remains neutral with regard to jurisdictional claims in published maps and institutional affiliations.

(c) (1) Open Access This article is licensed under a Creative Commons Attribution 4.0 International License, which permits use, sharing, adaptation, distribution and reproduction in any medium or format, as long as you give appropriate credit to the original author(s) and the source, provide a link to the Creative Commons licence, and indicate if changes were made. The images or other third party material in this article are included in the article's Creative Commons licence, unless indicated otherwise in a credit line to the material. If material is not included in the article's Creative Commons licence and your intended use is not permitted by statutory regulation or exceeds the permitted use, you will need to obtain permission directly from the copyright holder. To view a copy of this licence, visit http://creativecommons.org/licenses/by/4.0/.

(C) The Author(s) 2021 